\title{
Analysis of renin-angiotensin-aldosterone system gene polymorphisms in resistant hypertension
}

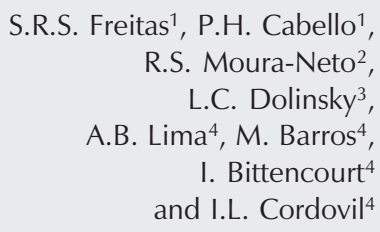

\author{
1Departamento de Genética, Fundação Oswaldo Cruz, Rio de Janeiro, RJ, Brasil \\ ${ }^{2}$ Departamento de Genética, Universidade Federal do Rio de Janeiro, \\ Rio de Janeiro, RJ, Brasil \\ ${ }^{3}$ Instituto de Biociências, UNIGRANRIO, Rio de Janeiro, RJ, Brasil \\ ${ }^{4}$ Divisão de Hipertensão, Instituto Nacional de Cardiologia Laranjeiras, \\ Rio de Janeiro, RJ, Brasil
}

\section{Correspondence}

S.R.S. Freitas

Laboratório de Genética

Departamento de Genética, FIOCRUZ

Pavilhão Leonidas Deane

Av. Brasil, 4365, Sala 615

21045-900 Rio de Janeiro, RJ

Brasil

Fax: +55-21-2260-4282

E-mail: sroig@ioc.fiocruz.br

Received May 9, 2006

Accepted December 18, 2006

\section{Abstract}

Essential hypertension is a disease multifactorially triggered by genetic and environmental factors. The contribution of genetic polymorphisms of the renin-angiotensin-aldosterone system and clinical risk factors to the development of resistant hypertension was evaluated in 90 hypertensive patients and in 115 normotensive controls living in Southwestern Brazil. Genotyping for insertion/deletion of angiotensin-converting enzyme, angiotensinogen M235T, angiotensin II type 1 receptor $\mathrm{A} 1166 \mathrm{C}$, aldosterone synthase C344T, and mineralocorticoid receptor A4582C polymorphisms was performed by PCR, with further restriction analysis when required. The influence of genetic polymorphisms on blood pressure variation was assessed by analysis of the odds ratio, while clinical risk factors were evaluated by logistic regression. Our analysis indicated that individuals who carry alleles 235-T, 1166-A, 344-T, or 4582-C had a significant risk of developing resistant hypertension $(\mathrm{P}<0.05)$. Surprisingly, when we tested individuals who carried the presumed risk genotypes A1166C, $\mathrm{C} 344 \mathrm{~T}$, and $\mathrm{A} 4582 \mathrm{C}$ we found that these genotypes were not associated with resistant hypertension. However, a gradual increase in the risk to develop resistant hypertension was detected when the 235-MT and TT genotypes were combined with one, two or three of the supposedly more vulnerable genotypes - A1166C (AC/AA), C344T (TC/TT) and A4582C (AC/CC). Analysis of clinical parameters indicated that age, body mass index and gender contribute to blood pressure increase $(\mathrm{P}<0.05)$. These results suggest that unfavorable genetic renin-angiotensin-aldosterone system patterns and clinical risk variables may contribute to increasing the risk for the development of resistant hypertension in a sample of the Brazilian population.
Key words - Essential hypertension

- Renin-angiotensinaldosterone system

- Polymorphisms

- Genetics 


\section{Introduction}

Essential hypertension, a complex syndrome determined by both genetic and environmental factors, affects approximately $25 \%$ of the world's population and consequently is considered to be one of the most common conditions for which individuals seek health care. According to the National Health and Nutrition Education Survey (1), most hypertensive patients are considered to be resistant because their blood pressure (BP) cannot be reduced to $<140 / 90 \mathrm{mmHg}$ with an appropriate triple-drug regimen, including an oral diuretic, with all agents administered at or near maximal dosages. Moreover, careful elimination of patient- and physicianrelated reasons of inadequate blood pressure control should lead to the diagnosis of truly resistant hypertension. The causes of refractory hypertension are multifactorial and therefore a better understanding of the physiological systems that contribute to this uncontrolled BP and of drug metabolism may help identify the causative factors.

In the past, genetic polymorphisms of candidate genes from physiological systems involved in BP control have been extensively tested. The renin-angiotensin-aldosterone system (RAAS) is one of the mechanisms that play key roles in the regulation of BP. Consequently, genes that encode components of the RAAS are thought to play a role in determining genetic susceptibility to essential hypertension and have been intensively scrutinized. Some of the polymorphisms associated with the various forms of hypertension are: the methionine $(\mathrm{M}) \rightarrow$ threonine $(\mathrm{T})$ variation at the amino acid position 235 of the angiotensinogen (AGT) gene (2), an insertion/deletion of the Alu fragment in the 16th intron of angiotensinconverting enzyme (ACE) (3), an A to C transversion at the nucleotide position 1166 of the AGT II receptor type 1 (AGTR1) (4) and the $\mathrm{T} \rightarrow \mathrm{C}$ substitution at the -344 locus in the promoter region of aldosterone syn- thase (CYP11B2) (5). Most of these polymorphisms are involved in specific physiological imbalance (6-8). However, contradictory findings have been obtained for different populations (9-14). The inconsistencies presented in RAAS gene-association studies exemplify the challenges of distinguishing among complex multifactorial traits, such as hypertension, by single-locus analysis. These inconsistencies might arise from population structure, varying effects of several disease-predisposition variants or geneenvironment interactions. Each of these factors can hinder the detection of a modest contribution by an individual locus to a trait such as hypertension. Subsequently, the screening of numerous molecular variations combined with environmental-clinical factors may help to elucidate the most important parameters that contribute to disease development in a particular population.

Assuming that hypertension is a result of a complex sum of external and clinical factors combined with genetic predisposition, we determined whether or not multiple polymorphisms in the RAAS pathway genes, as well as environmental-clinical risk factors, contributed to the development of resistant hypertension in a sample of Brazilian patients.

\section{Subjects and Methods}

\section{Study subjects}

A total of 205 Brazilian individuals (90 hypertensive and 115 normotensive subjects) from the city of Rio de Janeiro with similar anthropometric backgrounds were selected at the Hypertension Division of the Laranjeiras National Institute of Cardiology, Rio de Janeiro, RJ, Brazil. The hypertensive patients recruited had a diagnosis of uncontrolled hypertension based on conventional BP measurements (systolic BP (SBP) $\geq 140$ $\mathrm{mmHg}$ or diastolic BP (DBP) $\geq 90 \mathrm{mmHg}$ ) (15-17) and had been under treatment for $\geq 3$ 
months with a stable scheme consisting of $\geq 3$ antihypertensive drugs (including a diuretic), of adequate combination and dose (15). In patients with type 2 diabetes (15 individuals) the definition of hypertension was $\mathrm{BP} \geq 130 / 80 \mathrm{mmHg}$. Cases with secondary form hypertension were excluded. Normotensive controls were defined as those without a family history of hypertension or other cardiovascular disorders and $\mathrm{BP}<140$ / $90 \mathrm{mmHg}$. BP was measured on the left arm of the subject in the sitting position with a conventional mercury sphygmomanometer on three different occasions by the same observer (15).

The study was approved by the Committee for Research on Human Subjects of the Laranjeiras National Institute of Cardiology, and all subjects gave written informed consent to participate.

\section{Genotyping protocols}

Genomic DNA was extracted by a standard salting out method (18). Genotyping was performed by the PCR technique complemented with further restriction enzyme analysis when required. PCR was performed with a Perkin-Elmer 9600 apparatus. For all polymorphisms, 100 ng genomic DNA was amplified. PCR for all the markers was performed using $200 \mu \mathrm{m}$ of each deoxynucleotide triphosphate, $300 \mu \mathrm{m}$ of each primer and $0.5 \mathrm{U}$ of Taq polymerase in its specific buffer (Biotools, Mountain View, CA, USA) in a final volume of $10 \mu \mathrm{L}$. ACE gene I/D (19), AGT M235T (20), AGTR1 A1166C (21), CYP11B2 C344T (22), and mineralocorticoid receptor A4582C (23) were detected by PCR as described elsewhere. ACE PCR fragments were separated on $2.5 \%$ agarose gel and visualized by ethidium bromide staining. PCR products were digested with $5 \mathrm{U}$ Tth111I (AGT M235T), DdeI (AGTR1 A1166C), HaeIII (CYP11B2 C344T), and MspA1I (MR A4582C) restriction enzymes (New England Biolabs, Beverly, MA, USA) at $37^{\circ} \mathrm{C}$ overnight. The fragments were separated on 3\% agarose gels and stained with ethidium bromide and a Polaroid photo was taken for genotyping.

For quality control of these assays, samples from the hypertensive and normotensive groups were selected for regenotyping.

\section{Statistical analysis}

Clinical data were compared by the Student unpaired $t$-test for quantitative data and by the $\chi^{2}$ test for qualitative data. The genotype frequencies among the study participants were calculated using the SPSS statistical program, version 10.0 (Chicago, IL, USA), and allele frequencies were calculated based on the observed genotypes. The estimation of acceptable minor allelic frequency for RAAS polymorphisms was calculated by the following function:

$P \min =1-\left[1-(1-\alpha)^{1 / c}\right]^{1 / 2 n}$

where $\alpha=5 \%$ confidence interval; $\mathrm{C}=$ numbers of alleles; $n=$ number of individuals (24). Hardy-Weinberg equilibrium (HWE) for the distribution of the genotypes was estimated by the $\chi^{2}$ test using the GENIOC program (25). Allele and genotype frequencies were compared using $\chi^{2}$ test, by GENIOC. The influence of each RAAS polymorphism on blood pressure variation was assessed by analysis of odds ratio (OR) (Epi-Info statistical program, version 3.2.2, Atlanta, GA, USA). Next, we selected the genotypes whose association with arterial hypertension had already been established in previous studies, searching for the presence of additive effects of different RAAS polymorphisms by OR analysis. Logistic regression analysis of gender, age, glucose, body mass index (BMI), triglycerides, total cholesterol, HDL cholesterol, and LDL cholesterol was used to investigate the association between the anthropometric profile and the risk for hyper- 
tension. Regression analyses were calculated using the SPSS statistical program.

\section{Results}

The data concerning the clinical parameters of the normotensive and hypertensive groups reported as means \pm SD are summarized in Table 1. A statistically significant difference was observed between the two groups with respect to age, blood pressure level, and lipid profile $(\mathrm{P}<0.05)$.

The minimal allelic frequencies calculated for the hypertensive and normotensive groups were 0.020 and 0.042 , respectively. All allelic frequencies in both samples were higher than the predetermined minimum.

The genotypic and allelic frequency data for the hypertensive and normotensive groups are summarized in Table 2. Tests for HWE were carried out for all loci among the hypertensive and normotensive subjects separately. All polymorphisms analyzed were in HWE not only in patients $(\mathrm{P}>0.05)$ but also in normotensive subjects $(\mathrm{P}>0.05)$.

The allelic frequencies of M235T $(\mathrm{P}=$ $0.000)$ and $\mathrm{C} 344 \mathrm{~T}(\mathrm{P}=0.003)$ differed significantly between the normotensive and hypertensive groups. In both cases, the 235$\mathrm{T}$ and 344-T alleles (considered to represent

Table 1. Anthropometric and clinical characteristics of hypertensive patients and normotensive individuals from the city of Rio de Janeiro.

\begin{tabular}{lcc}
\hline & $\begin{array}{c}\text { Normotensive subjects } \\
(\mathrm{N}=115)\end{array}$ & $\begin{array}{c}\text { Hypertensive patients } \\
(\mathrm{N}=90)\end{array}$ \\
\hline Gender (female/male) & $57 / 59$ & $41 / 49$ \\
Age (years) & $51.85 \pm 8.57$ & $56.74 \pm 11.10^{*}$ \\
Glucose (mg/dL) & $109.39 \pm 26.14$ & $112.09 \pm 51.11$ \\
Body mass index (kg/m $\left.{ }^{2}\right)$ & $28.92 \pm 5.21$ & $30.11 \pm 4.78$ \\
Systolic blood prssure $(\mathrm{mmHg})$ & $120.08 \pm 7.02$ & $163.60 \pm 24.46^{*}$ \\
Diastolic blood pressure $(\mathrm{mmHg})$ & $78.11 \pm 5.28$ & $100.08 \pm 16.08^{*}$ \\
Total cholesterol $(\mathrm{mg} / \mathrm{dL})$ & $204.60 \pm 46.79$ & $200.64 \pm 38.36$ \\
Triglyceride $(\mathrm{mg} / \mathrm{dL})$ & $135.11 \pm 97.11$ & $147.96 \pm 71.76^{*}$ \\
HDL cholesterol $(\mathrm{mg} / \mathrm{dL})$ & $48.30 \pm 14.03$ & $49.44 \pm 14.57$ \\
LDL cholesterol $(\mathrm{mg} / \mathrm{dL})$ & $135.95 \pm 93.35$ & $117.03 \pm 56.26^{*}$ \\
& &
\end{tabular}

Data are reported as means \pm SD .

${ }^{*} \mathrm{P}<0.05$ compared to normotensive subjects (Student $t$-test). an increased risk for hypertension in this population) were expressively higher in hypertensive patients $(235-\mathrm{T}$ allele $=51.6 \%$; $344-\mathrm{T}$ allele $=61.5 \%)$ than in controls (235$\mathrm{T}$ allele $=25.2 \% ; 344-\mathrm{T}$ allele $=38 \%$ ). Comparative analyses of the allelic frequencies of I/D, A1166C, and A4582C did not show differences between groups.

The genotypic frequencies of M235T ( $\mathrm{P}$ $=0.000), \mathrm{A} 1166 \mathrm{C}(\mathrm{P}=0.007), \mathrm{C} 344 \mathrm{~T}(\mathrm{P}=$ $0.003)$, and $\mathrm{A} 4582 \mathrm{C}(\mathrm{P}=0.0492)$ differed significantly between groups due to the low frequency of at-risk alleles from the M235T (235-MM genotype), A1166C (1166-CC genotype), C344T (344-CC genotype), and A4582C (4582-AA genotype polymorphisms) in the normotensive subjects. The frequency of I/D polymorphisms did not differ between groups $(\mathrm{P}>0.05)$.

To investigate the genetic susceptibility to the development of resistant hypertension we performed OR analysis of the RAAS loci (Table 3). The results suggested an increased risk for hypertension or genetic susceptibility to this disease associated with 235-MT/ $\mathrm{TT}(\mathrm{OR}=3.20), 1166-\mathrm{AC} / \mathrm{AA}(\mathrm{OR}=5.13)$, $344-\mathrm{TC} / \mathrm{TT}(\mathrm{OR}=2.21)$, and 4582-AC/CC $(\mathrm{OR}=1.92)$. Intriguingly, when we considered jointly the A1166C, C344T and A4582C genotypes of a postulated worse genotype (Table 3), we observed that combinations among them did not modify the risk of resistant hypertension. However, haplotypes with 235-TT/MT (M235T-A1166C (MT/TT + AC/AA; OR = 8.67), M235T-C344T (MT/ $\mathrm{TT}+\mathrm{TC} / \mathrm{TT} ; \mathrm{OR}=8.90), \mathrm{M} 235 \mathrm{~T}-\mathrm{A} 4582 \mathrm{C}$ $(\mathrm{MT} / \mathrm{TT}+\mathrm{AC} / \mathrm{CC} ; \mathrm{OR}=8.10))$ displayed a substantial statistical risk for hypertension $(\mathrm{P}<0.05)$. The triplet combinations of M235T-A1166C-C344T, M235T-A1166C$\mathrm{A} 4582 \mathrm{C}$, and M235T-C344T-A4582C resulted in an increased OR $(\mathrm{OR}=10.93$, 10.10 , and 10.52, respectively). And finally, the M235T-A1166C-C344T-A4582C genotypic combination increased the OR concerning the chance of resistant hypertension to 12.49 . These results not only show that 
specific hypertension risk alleles contributed to the development of resistant hypertension, but also, and even more important, the presence of the 235-MT/TT genotypes associated with other unfavorable patterns of RAAS genes potentially increases the chance of developing this morbid disease.

Logistic regression was applied to identify the clinical-anthropometric parameters (age, gender, glucose, BMI, and lipid profile) that contribute to BP phenotypes. This method did not reveal significant effects of glucose (SBP: $\mathrm{P}=0.734$; DBP: $\mathrm{P}=0.448$ ), total cholesterol (SBP: $\mathrm{P}=0.859$; DBP: $\mathrm{P}=$ 0.798), HDL cholesterol (SBP: $\mathrm{P}=0.999$; DBP: $\mathrm{P}=0.997)$, LDL cholesterol (SBP: $\mathrm{P}=$ 0.150; DBP: $\mathrm{P}=0.172$ ), and triglycerides (SBP: $\mathrm{P}=0.285$; DBP: $\mathrm{P}=0.335$ ) on $\mathrm{BP}$. The variables with significant effects on $\mathrm{BP}$ were age (SBP: $\mathrm{b}=0.077, \mathrm{P}=0.000, \mathrm{OR}=$ 1.08; DBP: $b=0.057, \mathrm{P}=0.001, \mathrm{OR}=1.06$ ), BMI (SBP: $b=0.212, \mathrm{P}=0.000, \mathrm{OR}=1.24$; DBP: $b=0.195, P=0.000, O R=1.22)$, and gender (SBP: $\mathrm{b}=-1.033, \mathrm{P}=0.008, \mathrm{OR}=$ 2.81; DBP: $\mathrm{b}=-0.730, \mathrm{P}=0.051, \mathrm{OR}=$ 2.08). The predominant influences of age, BMI, and sex (female) agree with previous epidemiological studies showing that these parameters are important risk factors for hypertension $(26,27)$.

\section{Discussion}

Arterial hypertension involves interactions among genetic, environmental, demographic, vascular, and neuroendocrine factors. Essential hypertension is the most frequent diagnosis in this syndrome, indicating that the etiology has not been identified. However, a number of risk factors underlying essential hypertension have also been identified, including age, sex, and genetics. In some cases, the control of environmental risk factors associated with an appropriate drug/dose can normalize BP. However, patients with resistant hypertension probably have a genetic background that interferes with BP maintenance or with the pharmacokinetic/pharmacodynamic drug response. Previous studies have demonstrated that polymorphisms of the RAAS genes are related to several physiological changes (21$23,28,29)$. Thus, the combined action of multiple genes and environmental factors may contribute to disease severity. With the purpose of verifying this hypothesis, we investigated the genetic and anthropometric

Table 2. Genotype and allele frequency of renin-angiotensin-aldosterone system (RAAS) gene polymorphisms.

\begin{tabular}{|c|c|c|}
\hline RAAS polymorphisms & Normotensive subjects & Hypertensive patients \\
\hline \multicolumn{3}{|l|}{ AGT M235T genotypes } \\
\hline MM & $64(55.7 \%)$ & $26(28.6 \%)$ \\
\hline MT & $43(37.4 \%)$ & $35(38.5 \%)^{*}$ \\
\hline TT & $7(6.9 \%)$ & $30(33 \%)$ \\
\hline \multicolumn{3}{|l|}{ AGT alleles } \\
\hline M & $86(74.8 \%)$ & $44(48.4 \%)^{*}$ \\
\hline $\mathrm{T}$ & $29(25.2 \%)$ & $47(51.6 \%)^{*}$ \\
\hline \multicolumn{3}{|l|}{ ACE I/D genotypes } \\
\hline II & $12(10.5 \%)$ & $13(14.3 \%)$ \\
\hline ID & $52(45.2 \%)$ & $46(50.5 \%)$ \\
\hline DD & $51(44.3 \%)$ & $31(34.1 \%)$ \\
\hline \multicolumn{3}{|l|}{ ACE alleles } \\
\hline 1 & $38(38 \%)$ & $36(39.6 \%)$ \\
\hline $\mathrm{D}$ & $62(62 \%)$ & $55(60.4 \%)$ \\
\hline \multicolumn{3}{|c|}{ AGTR1 A1166C genotypes } \\
\hline AA & $58(50.4 \%)$ & $60(68.6 \%)$ \\
\hline$A C$ & $45(30.1 \%)$ & $29(32.2 \%)^{\star}$ \\
\hline $\mathrm{CC}$ & $12(10.5 \%)$ & $1(1.1 \%)$ \\
\hline \multicolumn{3}{|l|}{ AGTR1 alleles } \\
\hline A & $81(81 \%)$ & $76(83.5 \%)$ \\
\hline $\mathrm{C}$ & $19(19 \%)$ & $15(16.5 \%)$ \\
\hline \multicolumn{3}{|c|}{ CYP11B2 C344T genotypes } \\
\hline $\mathrm{CC}$ & $31(27 \%)$ & $13(14.3 \%)$ \\
\hline $\mathrm{TC}$ & $62(53.9 \%)$ & $43(47.3 \%)^{*}$ \\
\hline TT & $22(19.1 \%)$ & $35(38.5 \%)$ \\
\hline \multicolumn{3}{|l|}{ CYP11B2 alleles } \\
\hline C & $62(62 \%)$ & $35(38.5 \%)^{*}$ \\
\hline $\mathrm{T}$ & $38(38 \%)$ & $56(61.5 \%)^{\star}$ \\
\hline \multicolumn{3}{|l|}{ MR A4582C genotypes } \\
\hline AA & $60(52.2 \%)$ & $33(36.3 \%)$ \\
\hline$A C$ & $48(41.7 \%)$ & $47(51.6 \%)^{*}$ \\
\hline $\mathrm{CC}$ & $7(6.1 \%)$ & $11(12.1 \%)$ \\
\hline \multicolumn{3}{|l|}{ A4582C alleles } \\
\hline$A$ & $84(73.1 \%)$ & $56(61.5 \%)$ \\
\hline $\mathrm{C}$ & $31(26.9 \%)$ & 35 (38.5\%) \\
\hline
\end{tabular}


profile of resistant hypertensive patients and normotensive individuals.

The comparative analysis of allelic and genotypic frequencies established that A1166C polymorphism was expressed differently in the normotensive and hypertensive groups. The 1166-A allele, considered to be protective against hypertension according to Benetos et al. (30) and Nalogowska-Glosnicka et al. (21), was associated with resistant hypertension in our population sample. Almost $85 \%$ of patients had the 1166-A allele. These controversial results may be a sign of the relationship between 1166-A and $\mathrm{C}$ alleles indicating a different origin of hypertension. For this correlation to be confirmed, the physiological damage caused by this nucleotide alteration must be elucidated.

Comparative analysis also showed an increased frequency of 235-T and 344-T alleles as well as 235-TT and 344-TT genotypes in hypertensive individuals, as encountered in comparative gene-disease analysis $(2,8)$ or in population studies (11-14). The A4582C polymorphism has failed to reveal any correlation with hypertension in previous studies (23). In contrast with general previous belief, we detected a positive correlation between 4582-CC genotype and hypertension in Brazilian samples. However, the physiological damage caused by this genetic variant must be elucidated in order to validate our results.

OR analysis suggested that M235T, A1166C, C344T, and A4582C, tested individually, increased the risk for resistant hypertension. Intriguingly, combinations between A1166C, C344T, and A4582C were not associated with high-blood pressure phenotypes. However, it is very interesting to point out that a gradual risk increase towards resistant hypertension occurs when AGTMT and TT genotypes are combined with A1166C, C344T, and A4582C genotypes in the following sequence: M235T-A1166C (MT/TT + AC/AA), M235T-C344T (MT/ $\mathrm{TT}+\mathrm{TC} / \mathrm{TT}), \mathrm{M} 235 \mathrm{~T}-\mathrm{A} 4582 \mathrm{C}(\mathrm{MT} / \mathrm{TT}+$ AC/CC), M235T-A1166C-C344T (MT/TT + AC/AA + TC/TT), M235T-A1166C$\mathrm{A} 4582 \mathrm{C}(\mathrm{MT} / \mathrm{TT}+\mathrm{AC} / \mathrm{AA}+\mathrm{AC} / \mathrm{CC})$, M235T-C344T-A4582C (MT/TT + TC/TT $+\mathrm{AC} / \mathrm{CC})$, and M235T-A1166C-C344T$\mathrm{A} 4582 \mathrm{C}(\mathrm{MT} / \mathrm{TT}+\mathrm{AC} / \mathrm{AA}+\mathrm{TC} / \mathrm{TT}+\mathrm{AC} /$ $\mathrm{CC})$. This implies that the AGT-M235T geno-

Table 3. Odds ratio analysis of renin-angiotensin-aldosterone system polymorphisms.

\begin{tabular}{lc}
\hline Polymorphisms (genotypes at risk) & Odds ratio (95\% Cl) \\
\hline M235T (MT + TT) & $3.20(1.71-6.01)^{*}$ \\
I/D (ID + DD) & $0.70(0.28-1.75)$ \\
A1166C (AC + AA) & $5.13(1.05-34.13)^{*}$ \\
C344T (TC + TT) & $2.21(1.03-4.84)^{*}$ \\
A4582C (AC + CC) & $1.92(1.05-3.50)^{*}$ \\
M235T-A1166C (MT/TT + AC/AA) & $8.67(1.09-185.76)^{*}$ \\
M235T-C344T (MT/TT + TC/TT) & $8.90(1.32-235.33)^{*}$ \\
M235T-A4582C (MT/TT + AC/CC) & $8.10(1.83-101.34)^{*}$ \\
A1166C-C344T (AC/AA + TC/TT) & $1.61(0.83-3.11)$ \\
A1166C-A4582C (AC/AA + AC/CC) & $8.80(1.32-232.15)$ \\
C344T-A4582C (TC/TT + AC/CC) & $2.10(0.54-8.49)$ \\
M235T-A1166C-C344T (MT/TT + AC/AA + TC/TT) & $10.93(1.36-235.63)^{*}$ \\
M235T-A1166-A4582C (MT/TT + AC/AA + AC/CC) & $10.10(1.05-351.36)^{*}$ \\
M235T-C344T-A4582C (MT/TT + TC/TT + AC/CC) & $10.50(1.10-300.23)^{*}$ \\
A1166C-C344T-A4582C (AC/AA + TC/TT + AC/CC) & $3.10(0.81-2.10)$ \\
M235T-A1166C-C344T-A4582C (MT/TT + AC/AA + TC/TT + AC/CC) & $12.49(1.83-210.41)^{*}$ \\
\hline 95\% Cl = confidence interval at 95\%. & \\
${ }^{*} P<0.05$ compared to normotensive individuals $\left(\chi^{2}\right.$ test). &
\end{tabular}


type plays an important role in resistant hypertension since this gene seems to amplify the effects of specific genotypes of other RAAS genes.

Association analysis between the anthropometric profile and hypertension risk indicated that age, BMI, and sex were the most important risk factors for resistant hypertension development in Brazilian patients. The present results support previous clinical and epidemiological studies which prove that a sedentary life style, physical inactivity, smoking, dyslipidemia, and alcohol and sodium intake are also external factors influencing the development of hypertension (31-33).

Finally, the risk M235T-A1166C-C344T-
A4582C haplotype and clinical risk factors (sex, BMI, age) collaborate in the development of resistant hypertension observed in Brazilian patients. These data emphasize the need to test an extensive set of genetic and clinical biomarkers in cases of multifactorial diseases in order to obtain accurate results. The use of hypertension biomarkers may provide useful information on pathogenetic mechanisms and on subsequent therapeutic approaches in selected individuals. Furthermore, the genetic evaluation of RAAS molecular variants associated with clinical analysis may contribute to the personalized diagnosis of severe forms of hypertension in the future.

\section{References}

1. Burt VL, Whelton P, Roccella EJ, Brown C, Cutler JA, Higgins M, et al. Prevalence of hypertension in the US adult population. Results from the Third National Health and Nutrition Examination Survey, 1988-1991. Hypertension 1995; 25: 305-313.

2. Jeunemaitre $X$, Soubrier F, Kotelevtsev YV, Lifton RP, Williams CS, Charru A, et al. Molecular basis of human hypertension: role of angiotensinogen. Cell 1992; 71: 169-180.

3. Marre M, Bernadet P, Gallois Y, Savagner F, Guyene TT, Hallab M, et al. Relationships between angiotensin I converting enzyme gene polymorphism, plasma levels, and diabetic retinal and renal complications. Diabetes 1994; 43: 384-388.

4. Bonnardeaux A, Davies E, Jeunemaitre X, Fery I, Charru A, Clauser $\mathrm{E}$, et al. Angiotensin II type 1 receptor gene polymorphisms in human essential hypertension. Hypertension 1994; 24: 63-69.

5. Curnow KM, Tusie-Luna MT, Pascoe L, Natarajan R, Gu JL, Nadler $\mathrm{JL}$, et al. The product of the CYP11B2 gene is required for aldosterone biosynthesis in the human adrenal cortex. Mol Endocrinol 1991; 5: 1513-1522.

6. Bloem LJ, Manatunga AK, Tewksbury DA, Pratt JH. The serum angiotensinogen concentration and variants of the angiotensinogen gene in white and black children. J Clin Invest 1995; 95: 948-953.

7. Zhu X, Bouzekri N, Southam L, Cooper RS, Adeyemo A, McKenzie $C A$, et al. Linkage and association analysis of angiotensin I-converting enzyme (ACE)-gene polymorphisms with ACE concentration and blood pressure. Am J Hum Genet 2001; 68: 1139-1148.

8. Pojoga L, Gautier S, Blanc H, Guyene TT, Poirier O, Cambien F, et al. Genetic determination of plasma aldosterone levels in essential hypertension. Am J Hypertens 1998; 11: 856-860.

9. Schmidt S, van Hooft I, Grobbee DE, Ganten D, Ritz E. Polymorphism of the angiotensin I converting enzyme gene is apparently not related to high blood pressure: Dutch Hypertension and Offspring Study. J Hypertens 1993; 11: 345-348.

10. Vassilikioti S, Doumas M, Douma S, Petidis K, Karagiannis A,
Balaska K, et al. Angiotensin converting enzyme gene polymorphism is not related to essential hypertension in a Greek population. Am J Hypertens 1996; 9: 700-702.

11. Mettimano M, Lanni A, Migneco A, Specchia ML, Romano-Spica V, Savi L. Angiotensin-related genes involved in essential hypertension: allelic distribution in an Italian population sample. Ital Heart $J$ 2001; 2: 589-593.

12. Castellano M, Glorioso N, Cusi D, Sarzani R, Fabris B, Opocher G, et al. Genetic polymorphism of the renin-angiotensin-aldosterone system and arterial hypertension in the Italian population: the GENIPER Project. J Hypertens 2003; 21: 1853-1860.

13. Agachan B, Isbir $\mathrm{T}$, Yilmaz $\mathrm{H}$, Akoglu $\mathrm{E}$. Angiotensin converting enzyme I/D, angiotensinogen T174M-M235T and angiotensin II type 1 receptor A1166C gene polymorphisms in Turkish hypertensive patients. Exp Mol Med 2003; 35: 545-549.

14. Henderson SO, Haiman CA, Mack W. Multiple polymorphisms in the renin-angiotensin-aldosterone system (ACE, CYP11B2, AGTR1) and their contribution to hypertension in African Americans and Latinos in the multiethnic cohort. Am J Med Sci 2004; 328: 266-273.

15. European Society of Hypertension - European Society of Cardiology Guidelines Committee. 2003 European Society of Hypertension European Society of Cardiology guidelines for the management of arterial hypertension. J Hypertens 2003; 21: 1011-1053.

16. Chobanian AV, Bakris GL, Black HR, Cushman WC, Green LA, Izzo $\mathrm{JL} \mathrm{Jr}$, et al. The Seventh Report of the Joint National Committee on Prevention, Detection, Evaluation, and Treatment of High Blood Pressure: the JNC 7 report. JAMA 2003; 289: 2560-2572.

17. Pickering TG, Hall JE, Appel LJ, Falkner BE, Graves J, Hill MN, et al. Recommendations for blood pressure measurement in humans and experimental animals: Part 1: blood pressure measurement in humans: a statement for professionals from the Subcommittee of Professional and Public Education of the American Heart Association Council on High Blood Pressure Research. Hypertension 2005; 
45: $142-161$.

18. Lahiri DK, Numberger JI Jr. A rapid non-enzymatic method for the preparation of HMW DNA from blood for RFLP studies. Nucl Acids Res 1991; 19: 5444.

19. Rigat B, Hubert C, Alhenc-Gelas F, Cambien F, Corvol P, Soubrier F. An insertion/deletion polymorphism in the angiotensin I-converting enzyme gene accounting for half the variance of serum enzyme levels. J Clin Invest 1990; 86: 1343-1346.

20. Russ AP, Maerz W, Ruzicka V, Stein U, Gross W. Rapid detection of the hypertension-associated Met235 $\rightarrow$ Thr allele of the human angiotensinogen gene. Hum Mol Genet 1993; 2: 609-610.

21. Nalogowska-Glosnicka K, Lacka BI, Zychma MJ, Grzeszczak W, Zukowska-Szczechowska E, Poreba R, et al. Angiotensin II type 1 receptor gene $\mathrm{A} 1166 \mathrm{C}$ polymorphism is associated with the increased risk of pregnancy-induced hypertension. Med Sci Monit 2000; 6: 523-529.

22. Hautanena A, Lankinen L, Kupari M, Janne OA, Adlercreutz H, Nikkila $H$, et al. Associations between aldosterone synthase gene polymorphism and the adrenocortical function in males. $J$ Intern Med 1998; 244: 11-18.

23. Poch E, Gonzalez D, Giner V, Bragulat E, Coca A, de La Sierra A. Molecular basis of salt sensitivity in human hypertension. Evaluation of renin-angiotensin-aldosterone system gene polymorphisms. Hypertension 2001; 38: 1204-1209.

24. Budowle B, Monson KL, Chakraborty R. Estimating minimum allele frequencies for DNA profile frequency estimates for PCR-based loci. Int J Legal Med 1996; 108: 173-176.

25. Cabello PH, Krieger H. GENIOC: Sistema para análises de dados de genética. Rio de Janeiro: Instituto Oswaldo Cruz - FIOCRUZ. Publicação técnica; 1977.

26. Mikhail N, Golub MS, Tuck ML. Obesity and hypertension. Prog Cardiovasc Dis 1999; 42: 39-58.

27. Irigoyen MV, Lacchini S, De Angelis K, Michelini LC. Fisiopatologia da hipertensão: o que avançamos? Rev Soc Cardiol Estado de São Paulo 2003; 1: 20-45.

28. Kupari M, Hautanen A, Lankinen L, Koskinen P, Virolainen J, Nikkila $\mathrm{H}$, et al. Associations between human aldosterone synthase (CYP11B2) gene polymorphisms and left ventricular size, mass, and function. Circulation 1998; 97: 569-575.

29. Siani A, Russo P, Paolo CF, lacone R, Venezia A, Russo O, et al. Combination of renin-angiotensin system polymorphisms is associated with altered renal sodium handling and hypertension. Hypertension 2004; 43: 598-602.

30. Benetos A, Gautier S, Ricard S, Topouchian J, Asmar R, Poirier O, et al. Influence of angiotensin-converting enzyme and angiotensin II type 1 receptor gene polymorphisms on aortic stiffness in normotensive and hypertensive patients. Circulation 1996; 94: 698-703.

31. Perry IJ, Whincup PH, Shaper AG. Environmental factors in the development of essential hypertension. Br Med Bull 1994; 50: 246259.

32. Benetos A, Waeber B, Izzo J, Mitchell G, Resnick L, Asmar R, et al. Influence of age, risk factors, and cardiovascular and renal disease on arterial stiffness: clinical applications. Am J Hypertens 2002; 15: 1101-1108.

33. LaRosa JC, Brown CD. Cardiovascular risk factors in minorities. Am J Med 2005; 118: 1314-1322. 